\title{
The Relationship Between Organisational Culture and the Deployment of Systems Development Methodologies
}

\author{
Juhani Iivari $^{1}$ and Magda Huisman ${ }^{2}$ \\ ${ }^{1}$ Department of Information Processing Science, University of Oulu, P.O.Box 3000, \\ 90014 Oulun yliopisto, Finland \\ iivari@rieska.oulu.fi \\ 2 Department of Computer Science and Information Systems, \\ Potchefstroom University for CHE, Private Bag X6001, Potchefstroom, 2531, \\ South Africa \\ rkwhmh@puknet.puk.ac.za
}

\begin{abstract}
This paper analyses the relationship between organisational culture and the perceptions of use, support and impact of systems development methodologies (SDMs) interpreting organisational culture in terms of the competing values model. The results show that organisations with different culture differ in their perceptions concerning the support provided by SDMs and in their perceptions concerning the impact of SDMs on the quality of developed systems and the quality and productivity of the systems development process. The results depend, however, on the respondent groups (developers vs. managers). The findings also suggest that the deployment of SDMs is primarily associated with the hierarchical culture which is oriented toward security, order and routinisation. Also managers' criticality towards the deployment of SDMs in organisation with high rational culture (focusing on productivity, efficiency and goal achievement) is noteworthy.
\end{abstract}

\section{Introduction}

This paper investigates the relationship between organisational culture and the deployment of systems development methodologies (SDMs). There are a number of reasons for the selection of this topic. Firstly, SDMs have formed one of the central topics in Information Systems and Software Engineering. In spite of the huge effort devoted to their development and the pressure to adopt them [9] their practical usefulness is still a controversial issue ([9],[11]). Secondly, very little is known about the actual usage of SDMs. A recent survey of research on SDMs [33] identifies only 19 papers addressing SDM usage, of which 12 have been published since 1990. The recent surveys indicate, however, quite consistently that many organisations claim that they do not use any SDMs (e.g. [5],[13],[27]). Thirdly, most literature on the use of SDMs is descriptive. It does not attempt to explain the use of SDMs.

This study goes beyond the existing literature in the sense that it analyses the relationship between organisational culture and the deployment of SDMs. There are sev- 
eral reasons for the selection of organisational culture as the focus of this study. Firstly, organisations tend to develop specific cultures. These form a context in which systems development (SD) and the deployment of SDMs takes place. Secondly, organisational culture is a rich concept, comprising of symbols, heroes, rituals and values [15]. Therefore SDMs can be conceived to be part of an organisational culture. Wastell [30], for example, argues that a SDM may provide an organisational ritual with the primary function to serve as a social defence against the anxieties and uncertainties of SD rather than as an efficient and effective means of developing systems. Thirdly, the role of organisational culture as a significant source of organisational inertia is well known ([4],[28]). There is also an emerging interest in the influence of culture on the acceptance of IT [25]. Our assumption is that organisational culture may also be influential in the acceptance of SDMs, too.

The organisational culture of a large organisation cannot be expected to be homogenous but it consists of a number of subcultures [29]. Recognising this plurality, we decided to focus on cultures of IS departments, because they can be expected to be most closely associated with the behaviour of IS developers. This study applies a specific model of organisational culture, a competing values model [31], to analyse the relationship between the organisational culture and the usage of SDMs. The next section explains the competing values model in greater detail. Section 3 introduces the research design and section 4 the results. Section 5 discusses the findings and makes some concluding comments.

\section{Organisational Culture, the Competing Values Framework and Deployment of Systems Development Methodologies}

\subsection{Organisational Culture}

Organisational culture is a versatile concept that has been used in several meanings ([1],[29]). Despite the differences, there seems to be an agreement that an organisational culture includes several levels with a varying degree of awareness by the culture-bearers. Schein [28] suggests that the deepest level consists of patterns of basic assumptions that the organisational members take as granted without awareness. At the surface level lie artefacts as the visible and audible patterns of the culture. The intermediate level covers values and beliefs, concerning what 'ought' to be done. Similarly, [15] proposes a model for manifestations of organisational culture, including symbols, heroes, rituals and values. In this framework symbols are at the most superficial level and values at the deepest level.

Research into organisational culture has mostly been qualitative. This is related with the distinction whether a culture is seen to be unique to each organisation or whether it is seen to include significant universal aspects [7]. Studies emphasising uniqueness have often been qualitative, whereas those assuming universality have more often been quantitative. Despite the dominance of the qualitative tradition, there has been some efforts to develop quantitative "measures" for organisational culture (e.g. [15]). This paper applies a specific quantitative model of organisational culture, 
the competing values framework ([7],[23],[24]). As its name suggests, it focuses on values as core constituents of organisational culture.

\subsection{The Competing Values Framework}

The competing values framework is based on two distinctions: change vs. stability and internal focus vs. external focus. Change emphasises flexibility and spontaneity, whereas stability focuses on control, continuity and order. The internal focus underlines integration and maintenance of the sociotechnical system, whereas the external focus emphasises competition and interaction with the organisational environment [7]. The opposite ends of each of these dimensions pose competing and conflicting demands on the organisation.

Based on the two dimensions, one can distinguish four organisational culture types. The group culture (GC) with change and internal focus has a primary concern with human relations and flexibility. Belonging, trust, and participation are core values. Effectiveness criteria include the development of human potential and member commitment. The developmental culture (DC) with change and external focus is future-oriented considering what might be. The effectiveness criteria emphasise growth, resource acquisition, creativity, and adaptation to the external environment. The rational culture (RC) with stability and external focus is very achievement-oriented, focusing on productivity, efficiency and goal achievement. The hierarchical culture (HC) with stability and internal focus is oriented toward security, order and routinisation. It emphasises control, stability and efficiency through following regulations ([7],[23]). Each of the culture types has its polar opposites [7]. The GC, which emphasises flexibility and internal focus, is contrasted with the RC, stressing control and external focus. The DC, which is characterised by flexibility and external focus, is opposed by the HC, which emphasises control and internal focus.

The four cultural types are ideal types in the sense that organisations are unlikely to reflect only one culture type [7]. In fact, the competing values model stresses a reasonable balance between the opposite orientations, even though some culture types may be more dominant than others [7]. This imposes paradoxical requirements for effective organisations ([3],[20],[22]).

Cooper [6] applied the competing values model to understand IT implementation. He proposed that different ISs may support alternative values, and that when an IS conflicts the organisational culture (values), the implementation of the system will be resisted. These implementation problems may lead to underutilisation of the system, if implemented, and to the adaptation of the system to the existing culture. The latter may lead to more conservative development as initially planned. This paper applies the model to analyse the deployment of SDMs to be discussed next.

\subsection{Deployment of Systems Development Methodologies}

This paper uses the term "methodology" to cover the totality of SD approaches (such as the structured approach, information modelling approach, object-oriented 
approach), process models (such as the linear life-cycle, prototyping, evolutionary development, spiral models), specific methods (e.g. MSA, IE, NIAM, OMT, UML, ETHICS) and specific techniques.

Deployment encapsulates the post-implementation stages of the innovation diffusion process, where the innovation is actually being used and incorporated into the organisation [26]. This focus on the deployment of SDMs is necessary because adopted SDMs might not be used effectively, might not be used at all or might not have the intended consequences. The deployment of SDMs can be analysed from several perspectives. In this paper we focused on the use of SDMs, the perceived support it provides, and its impact on the developed system and the development process. Accordingly, the following seven perspectives were selected:

1. maximum intensity of methodology use (vertical use)

2. methodology use across the organisation (horizontal use)

3. perceived methodology support as production technology

4. perceived methodology support as control technology

5. perceived methodology support as cognitive \& co-operation technology

6. perceived impact on the quality of developed systems

7. perceived impact on the quality and productivity of the development process

The first and second perspectives were suggested in [21]. The third, fourth and fifth ones are adapted from [14]. [14] developed and empirically tested a functional model for IS planning and design aids that distinguishes two major functional categories: production technology and co-ordination technology. The functionality of production technology "directly impacts the capacity of individual(s) to generate planning or design decisions and subsequent artifacts or products". The co-ordination technology defined as "functionality that enables or supports the interactions of multiple agents in the execution of a planning or design task" comprises control functionality and co-operative functionality. The control functionality "enables the user to plan for and enforce rules, policies or priorities that will govern or restrict the activities of team members during the planning and design process". The co-operative functionality enables the user "to exchange information with another individual(s) for the purpose of influencing (affecting) the concept, process and product of the planning/design team"1.

${ }^{1}$ [14] also identifies organisational technology consisting of two additional functionalities: support functionality "to help an individual user understand and use a planning and design aid effectively" and infrastructure defined as "standards that enable portability of skills, knowledge, procedures, or methods across planning or design processes". The support functionality can be interpreted as a functionality' in the sense that it supports the utilisation of all the basic functionalities. One of the findings of [14] was that the support functionality was difficult for respondents to clearly differentiate. The infrastructure component resulted from the feedback during the study and its differentiation was not tested empirically in [14]. We see infrastructure functionalities such as standards to support cooperation. 


\subsection{Organisational Culture and Systems Development Methodologies}

The competing values model can also be applied to IS departments, emphasising that the effectiveness of an IS department imposes paradoxical requirements of balancing opposite cultural orientations. In the following organisational culture is confined to this specific context. The paradoxical nature implies that the relationship between the organisational culture and SDM deployment may be quite complicated. The direction of causality may be in either of the two directions, i.e. culture influences the deployment of SDMs or vice versa. This paper takes a view that it is interactive. The relationship may also be either reinforcing or complementary. The former implies that a SDM reinforces the existing culture and the latter that it complements it in some way. To exemplify the former case, organisations with a HC may use SDMs as means of imposing security, order and routinisation. On the other hand, one can conceive that organisations with a DC, for example, may also perceive SDMs as means of imposing necessary security, order and routinisation.

Because of the above complexities we are not prepared to put forward any specific hypotheses about the relationship between organisational culture and SDMs. Instead we will focus on the research question. Does organisational culture, when applied to IS departments, have any relationship with the deployment of SDMs?

\section{$3 \quad$ Research Design and Method}

To analyse organisational cultures of IS departments we decided to focus on the culture perceptions of IS developers rather than of IT managers in order not to associate culture with IT managers' view of the desirable culture to be imposed on the IS department. In the case of the deployment of SDMs we decided to study both IS developer's and IT managers' perceptions. One reason for this is the possible bias brought by the research design where the same respondents (i.e. IS developers) assess both the organisational culture and deployment of SDMs. Our research design allows intergroup analysis where the culture is assessed by IS developers and the deployment by IT managers. One should note, however, that the purpose of this study is not a systematic comparison of IT managers' and IS developers' perceptions (some of these are reported in [16]).

\subsection{The Survey}

This study is part of a larger survey on SDM use in South Africa, which was conducted between July and October 1999. The 1999 IT Users Handbook (the most comprehensive reference guide to the IT industry in South Africa) was used and the 443 listed organisations were contacted via telephone to determine if they were willing to participate in the study. 213 organisations agreed to take part. A package of questionnaires was sent to a contact person in each organisation who distributed it. This package consisted of one questionnaire to be answered by the IT manager, and a 
number of questionnaires to be answered by individual IS developers in the organisation. The number of developer questionnaires was determined for each organisation during the telephone contacts. The response rate is given in Table 1 . The responses came from organisations representing a variety of business areas, manufacturing $(33 \%)$ and finance/banking/insurance (15\%) as the major ones. At the individual level the respondents reported considerable experience in SD, $22 \%$ between 3 and 5 years, $23 \%$ between $5-19$ years and $38 \%$ more than 10 years.

Table1. Response rate of survey

\begin{tabular}{|l|c|c|c|}
\hline & $\begin{array}{c}\text { Number } \\
\text { Distributed }\end{array}$ & $\begin{array}{c}\text { Number } \\
\text { Returned }\end{array}$ & $\begin{array}{c}\text { Response } \\
\text { Rate (\%) }\end{array}$ \\
\hline Organisations & 213 & 83 & 39.0 \\
\hline Developers & 893 & 234 & 26.2 \\
\hline Managers & 213 & 73 & 34.3 \\
\hline
\end{tabular}

\subsection{Measurement}

All the questions, except organisational culture and horizontal methodology use, were addressed to both developers and managers. Only developers evaluated the organisational culture, and the horizontal methodology use was assessed only by managers.

Multiple items were used to measure the perceived support provided by SDMs and its impact on the developed system and the development process. This resulted in a large data set. In order to reduce the data set, factor analysis using the principal components method with varimax normalised rotation on the data was performed. The Kaiser criterion was used to determine the number of factors to retain. This was followed by reliability analysis (Cronbach's alpha) on the items of each of the factors identified. We used a cutoff value 0.6 for acceptable reliability.

Organisational culture was measured using the instrument suggested in [34]. It includes 12 items, three items measuring each culture orientation. The reliability of the 3-item measure for the GC was 0.68 and the reliability of the measure for the DC was 0.69 . Reliability analysis indicated that one item of the 3 -item measure of the HC and one item of the 3-item measure for the RC decreased substantially the reliability. After deleting the two items, the reliability of the 2-item measures for the $\mathrm{HC}$ and for the DC were 0.71 and 0.71 , respectively. The indexes for each of the culture types was computed as averages of the two or three items included in the measure.

Vertical methodology use was measured as the maximum intensity of organisational usage of 29 listed methods, possible other standard (commercial) methods and possible in-house developed methods. Horizontal methodology use was measured using two items, namely the proportion of projects that are developed in the IS department by applying SDM knowledge, and the proportion of people in the IS department that apply SDM knowledge regularly. The reliability of these two items was 0.89 .

As explained above the distinction between perceived methodology support as production technology, perceived methodology support as control technology and per- 
ceived methodology support as cognitive and co-operation technology was adapted from [14]. However, the nature of the survey did not allow the use of their detailed questions to measure these functionalities, but this study adopted a shorter version.

Perceived methodology support as production technology was measured using eleven items. Factor analysis using the developer data gave only one factor and using the manager data three factors: "Support for organisational alignment" with five items, "Support for technical design" with three items and "Support for verification and validation" with two items. The following analysis uses the more refined factor structures. The reliability of the first factor was $0.90 / 0.91$, of the second factor $0.85 / 0.82$, of the third factor $0.83 / 0.86 .^{2}$

Perceived methodology support as control technology was measured using nine items. Separate factor analyses based on the developer data and the manager data gave only one factor. Its reliability was 0.94/0.92. Perceived methodology support as cognitive and co-operation technology was measured using eleven items. Separate factor analyses based on the developer data and the manager data gave very similar factor structures, comprising two factors: "Support for the common conception of systems development practice" with nine items and "Support for the evaluation of systems development practice" with two items. The reliability of the former factor was $0.92 / 0.92$ and of the second factor $0.79 / 0.92$.

Perceived methodology impact on the quality of the developed systems was measured using eight items adopted from ISO 9126 standard [19]. Separate factor analyses based on both developer data and manager data gave only factor. Its reliability was 0.95/0.93. Perceived methodology impact on the quality and productivity of the development process was measured using ten items. Factor analysis using the developer data gave only on factor. Factor analysis based on the manager data gave two factors: "Productivity effects and morale" with five items, and "Quality effects, goal achievement and reputation" with five items. The reliability of the first factor was $0.89 / 0.90$ and of the second factor $0.88 / 0.86$.

\subsection{Data Analysis}

Data analysis was performed using Statistica (version 5) software. Indexes of the four organisational culture types for each organisation were calculated as averages of the developer responses from that organisation. In the case of all other variables, individual developer and manager responses were aggregated separately to the organisational level calculating the aggregated responses as means of individual responses. The developer and manager responses were analysed separately.

To derive empirically the organisational culture, cluster analysis is used. After identifying clusters ANOVA/MANOVA is used to analyse the differences in the perceptions of use, support, and impact of SDMs. Finally, multiple regression analysis is used to investigate in more detail the relationship between the four cultural orientations and the perceptions of use, support and impact of SDMs.

2 The figure before the slash refers to the developer data and the figure after the slash to the manager data. 
Table 2. Results of cluster analysis

\begin{tabular}{|l|c|c|c|c|}
\hline & \multicolumn{1}{|c|}{$\begin{array}{c}\text { Cluster 1 } \\
(\mathrm{n}=26)\end{array}$} & $\begin{array}{l}\text { Cluster 2 } \\
(\mathrm{n}=18)\end{array}$ & $\begin{array}{l}\text { Cluster 3 } \\
(\mathrm{n}=13)\end{array}$ & \multicolumn{1}{c|}{$\begin{array}{l}\text { Cluster 4 } \\
(\mathrm{n}=12)\end{array}$} \\
\hline Group culture (GC) & 3.1 & 3.6 & 2.7 & 3.9 \\
\hline $\begin{array}{l}\text { Development culture } \\
\text { (DC) }\end{array}$ & 2.9 & 3.4 & 2.2 & 3.8 \\
\hline Hierarchical culture (HC) & 2.9 & 1.9 & 2.3 & 3.4 \\
\hline Rational culture (RC) & 3.5 & 3.7 & 2.4 & \multicolumn{1}{|c|}{4.0} \\
\hline Interpretation of clusters & $\begin{array}{l}\text { Moderate } \\
\text { rationally } \\
\text { oriented } \\
\text { culture }\end{array}$ & $\begin{array}{l}\text { Moderate } \\
\text { non-hie- } \\
\text { rarchical } \\
\text { culture }\end{array}$ & $\begin{array}{l}\text { Weak group- } \\
\text { oriented cul- } \\
\text { ture }\end{array}$ & $\begin{array}{l}\text { Strong com- } \\
\text { prehensive } \\
\text { culture }\end{array}$ \\
\hline
\end{tabular}

\section{Results}

\subsection{Organisational Culture of IS Departments}

In order to derive the organisational culture of an IS department, cluster analysis was conducted as K-means clustering using the four indicators of culture as clustering variables. Experimenting with alternative number of clusters (3-5), a four cluster solution turned out as the easiest to interpret (Table 2). It shows that IS departments can have one of the following cultures: a moderate rationally oriented culture, a moderate non-hierarchical culture, a weak group-oriented culture, or a strong comprehensive culture.

\subsection{Differences in the Deployment of SDMs among IS Departments with Different Organizational Culture}

ANOVA/MANOVA was used to test whether any differences exist in the SDM deployment among IS departments within the different culture clusters. Neither vertical methodology use nor horizontal methodology use differed between the four clusters.

As explained in section 3.2, the perceived support provided by SDMs is measured using the following three perspectives: Perceived support as production technology, perceived support as control technology, and perceived support as cognitive \& cooperation technology. Table 3 shows the perceived methodology support as production technology in the four cultural clusters. The results of MANOVA indicated that the vector consisting of support for organisational alignment, support for technical design and support for verification and validation differ between the culture clusters for both the developers' perceptions (Wilks' Lambda $=0.75$ at the level of $\mathrm{p} \leq 0.10$ ) and the managers' perceptions (Wilks' Lambda $=0.70$ at the level of $\mathrm{p} \leq 0.10$ ). When we consider the individual factors used to measure perceived support as production technology, $\mathrm{F}$ values shows that managers see support for organisational alignment to differ significantly between the clusters, whereas developers see support for the technical design and support for verification and validation to differ between them. 
Table 3. Differences in perceived SDM support as production technology among the organisational culture clusters

\begin{tabular}{|l|c|c|c|}
\hline & $\begin{array}{c}\text { Support for organi- } \\
\text { sational alignment }\end{array}$ & $\begin{array}{c}\text { Support for } \\
\text { technical design }\end{array}$ & $\begin{array}{c}\text { Support for verifica- } \\
\text { tion and validation }\end{array}$ \\
\hline $\begin{array}{l}\text { Moderate rationally } \\
\text { oriented culture }\end{array}$ & De: 3.4 & De: 3.4 & De: 3.3 \\
Ma: 3.8 & Ma: 3.5 & Ma: 3.0 \\
\hline $\begin{array}{l}\text { Moderate non-hierar- } \\
\text { chical culture }\end{array}$ & De 3.2 & De: 3.3 & De: 3.0 \\
\hline $\begin{array}{l}\text { Weak group-oriented } 2.8 \\
\text { culture }\end{array}$ & De: 3.1 & Ma: 3.1 & Ma: 2.3 \\
\hline $\begin{array}{l}\text { Strong comprehen- } \\
\text { sive culture }\end{array}$ & Ma: 4.0 & De: 3.0 & Ma: 3.4 \\
\hline F & Ma: 3.5 & De: 3.7 & Ma: 3.0 \\
\hline & De: $2.22^{\prime}$ & Ma: 3.5 & De: 3.7 \\
& Ma: $4.25^{*}$ & Ma: $0.78^{*}$ & De: $4.11^{*}$ \\
\hline
\end{tabular}

'p $\leq 0.10 \quad * \mathrm{p} \leq 0.05 \quad * * \mathrm{p} \leq 0.01 \quad * * * \mathrm{p} \leq 0.001$

Table 4. Differences in perceived SDM support as cognitive \& cooperation technology among the organisational culture clusters

\begin{tabular}{|l|c|c|}
\hline & $\begin{array}{c}\text { Support for the common con- } \\
\text { ception of SD practice }\end{array}$ & $\begin{array}{c}\text { Support for the evaluation of SD } \\
\text { practice }\end{array}$ \\
\hline $\begin{array}{l}\text { Moderate rationally } \\
\text { oriented culture }\end{array}$ & De: 3.2 & De: 3.3 \\
Ma: 3.6 & Ma: 3.7 \\
Moderate non-hier- & De: 3.0 & De: 3.1 \\
archical culture & Ma: 3.0 & Ma: 2.3 \\
\hline Weak group-ori- & De: 3.0 & De: 2.9 \\
ented culture & Ma: 3.2 & Ma: 3.6 \\
\hline $\begin{array}{l}\text { Strong compre- } \\
\text { hensive culture }\end{array}$ & De: 3.5 & De: 3.3 \\
\hline \multicolumn{1}{|c|}{ Ma: 3.4} & Ma: 3.5 \\
\hline & De: 1.59 & De: 0.78 \\
& Ma: 1.61 & Ma: $4.85 * *$ \\
\hline
\end{tabular}

'p $\leq 0.10 \quad * \mathrm{p} \leq 0.05 \quad * * \mathrm{p} \leq 0.01 \quad * * * \mathrm{p} \leq 0.001$

Perceived methodology support as control technology did not differ significantly between the four clusters in any respondent groups. However, organisation with a strong comprehensive culture generally reported the highest values and organisations with a moderate non-hierarchical culture the lowest values.

Table 4 depicts the perceived methodology support as cognitive \& co-operation technology in the four cultural clusters. The results of MANOVA indicate that the vector consisting of support for the common conception of SD practice and support for the evaluation of SD practice differ between the culture clusters for the managers' perceptions (Wilks' Lambda $=0.72$ at the level of $\mathrm{p} \leq 0.05$ ), but not for the developers' perceptions. When we consider the individual factors used to measure perceived support as cognitive \& co-operation technology, F values show that managers' perceptions differ significantly in the four clusters, especially the perceptions of the support for the evaluation of SD practice. 
Table 5. Differences in perceived SDM impact on the quality of the developed system and the quality and productivity of the development process among the organisational culture clusters

\begin{tabular}{|l|c||c|c|}
\hline & $\begin{array}{c}\text { Impact on the quality } \\
\text { of developed systems }\end{array}$ & $\begin{array}{c}\text { Productivity effects } \\
\text { and morale }\end{array}$ & $\begin{array}{c}\text { Quality effects, goal } \\
\text { achievement and } \\
\text { reputation }\end{array}$ \\
\hline $\begin{array}{l}\text { Moderate rational- } \\
\text { ly oriented culture }\end{array}$ & De: 3.4 & De: 3.2 & De: 3.3 \\
Ma: 3.7 & Ma: 3.6 & Ma: 3.7 \\
\hline $\begin{array}{l}\text { Moderate non- } \\
\text { hierarchical culture }\end{array}$ & De 3.4 & De: 3.3 & De: 3.2 \\
\hline Weak group- & De: 3.0 & Ma: 3.2 & Ma: 3.4 \\
oriented culture & Ma: 3.6 & De 2.9 & Ma: 3.1 \\
\hline $\begin{array}{l}\text { Strong comprehen- } \\
\text { sive culture }\end{array}$ & De: 3.8 & De: 3.6 & De: 3.7 \\
\hline $\mathrm{F}$ & Ma: 3.3 & Ma: 3.0 & Ma: 3.1 \\
\hline \multirow{2}{*}{$\mathrm{p} \leq 0.10$} & De: $3.02 *$ & De: 2.72 \\
Ma: 1.33 & Ma: 0.80 & De: 2.32 \\
*p $\leq 0.05$ & $* * \mathrm{p} \leq 0.01$ & Ma: 1.21 \\
\hline
\end{tabular}

Perceived impact of SDMs was measured using two perspectives, namely the perceived impact on the quality of the developed system, and the perceived impact on the quality and productivity of the development process. When we consider the perceived impact on the quality of the developed system in the second column of Table 5, we find that only developer perceptions differed between the four clusters.

The last two columns of Table 5 report the perceived methodology impact on the quality and productivity of the development process. The results of MANOVA indicate that the vector consisting of productivity effects and morale, and quality effects, goal achievement and reputation, differ between the culture clusters for the developers' perceptions (Wilks' Lambda $=0.82$ at the level of $\mathrm{p} \leq 0.10$ ), but not for the managers' perceptions. F values show significant $(\mathrm{p} \leq 0.10)$ differences between the clusters in the case of developer perceptions, when productivity effects and morale, and quality effects, goal achievement and reputation are considered individually.

\subsection{The Relationhips between Culture Orientations and the Deployment of SDMs}

The above analysis indicates that organisations with different organisational cultures perceive the methodology support for SD differently. Developers also see significant differences in the SDMs' impact on the quality of the developed systems and the productivity and quality of the SD process. Because the empirically derived clusters of culture were synthetic, it is difficult to conclude which of the four culture orientations may explain differences between the clusters. To test this regression analysis was used considering each of the use, support areas and impact dimensions as the dependent variable and the four indicators of organisational culture as the independent variables.

Multiple regression analysis assumes (1) interval or ratio scale measurement, (2) linearity, (3) homoscedasticity, i.e. the constancy of the residuals across the values of 
the predictor variables, (4) independence of residuals, (5) normality of residuals and (6) no multicollinearity [12]. Billings and Wroten [2] assess that the assumption of equal interval is not critical concluding that carefully constructed measures employing reasonable number of values and containing multiple items will yield data with sufficient interval properties. Linearity of the relationships was tested visually using the standardised residual and partial regression plots. None of the variables violated this assumption. Homoscedasticity was tested visually, using the standardised residual and observed values plots. None of the variables violated this assumption. Independence of residuals was assessed using the Durbin-Watson statistics which ranges from $0-4$, with the value 2 indicating that there is no autocorrelation. In the case of the manager data the values varied between 1.65 and 2.06, and in the case of the developers between 1.67 and 2.13 , with the exception of vertical use which had a value of 1.42. Normality of residuals was assessed using the modified Kolmogorov-Smirnov test (Lilliefors). Violations were detected $(\mathrm{p}<0.05)$ in the regressions with vertical use as the dependent variable for both the manager and the developer data. Multicollinearity was tested using the tolerance values. The lowest tolerance value in the case of the developer data was 0.43 and in the case of the manager data it was 0.40 . These values far exceeded the cutoff value of 0.01 as suggested by [12]. Taken together, the specific assumptions of multiple regression analysis were reasonable satisfied.

Table 6. The relationship between culture orientations and methodology use

\begin{tabular}{|c|c|c|}
\hline & $\begin{array}{l}\text { Vertical methodology } \\
\text { use }\end{array}$ & $\begin{array}{l}\text { Horizontal methodology } \\
\text { use }\end{array}$ \\
\hline & $\beta$ & $\beta$ \\
\hline Group culture (GC) & $\begin{array}{l}\text { De: }-0.24 \\
\text { Ma: } 0.14\end{array}$ & $\begin{array}{c}\text { De: - } \\
\text { Ma: }-0.06\end{array}$ \\
\hline Developmental culture (DC) & $\begin{array}{l}\text { De: }-0.03 \\
\text { Ma: } 0.20\end{array}$ & $\begin{array}{c}\text { De: - } \\
\text { Ma: } 0.09\end{array}$ \\
\hline Hierarchical culture (HC) & $\begin{array}{l}\text { De: } 0.25 \\
\text { Ma: } 0.19\end{array}$ & $\begin{array}{c}\text { De: - } \\
\text { Ma: } 0.10\end{array}$ \\
\hline Rational culture (RC) & $\begin{array}{l}\text { De: }-0.02 \\
\text { Ma: }-0.34\end{array}$ & $\begin{array}{c}\text { De: }- \\
\text { Ma: }-0.21\end{array}$ \\
\hline $\begin{array}{l}\mathrm{R}^{2} \\
\text { Adjusted } \mathrm{R}^{2}\end{array}$ & $\begin{array}{l}\text { De: } 0.12 \\
\text { Ma: } 0.07 \\
\text { De: } 0.06 \\
\text { Ma: } 0.00\end{array}$ & $\begin{array}{c}\text { De: - } \\
\text { Ma: } 0.04 \\
\text { De: - } \\
\text { Ma: }-0.04\end{array}$ \\
\hline $\mathrm{p} \leq 0.10$ & $* * \mathrm{p} \leq 0.01$ & $* * * \mathrm{p} \leq 0.001$ \\
\hline
\end{tabular}

Table 6 reports the relationship between the strength of each culture dimension and methodology use. It shows that the four dimensions of culture are weak predictors of use. Only when developers assessed the vertical use the four dimensions explained methodology use to a significant degree $(\mathrm{p} \leq 0.10)$. In that case the dimension of HC was significantly associated with the vertical use.

Table 7 shows the relationship between the cultural dimensions and factors of perceived methodology support as production technology. It indicates that the four cul- 
ture dimensions explain significantly the methodology support as production technology as perceived by developers. Among the cultural dimensions especially the strength of the $\mathrm{HC}$ and partly also the DC are positively associated with the perceived methodology support as production technology. The RC on the other hand is predominantly negatively associated with manager perceptions of methodology support as production technology, even though most of the regression coefficients are not statistically significant.

Table 7. The relationship between culture orientation and perceived support as production technology

\begin{tabular}{|c|c|c|c|}
\hline & $\begin{array}{l}\text { Support for organ- } \\
\text { isational alignment }\end{array}$ & $\begin{array}{l}\text { Support for techni- } \\
\text { cal design }\end{array}$ & $\begin{array}{l}\text { Support for verifi- } \\
\text { cation and validation }\end{array}$ \\
\hline & $\beta$ & $\beta$ & $\beta$ \\
\hline Group culture (GC) & $\begin{array}{l}\text { De: }-0.02 \\
\text { Ma: }-0.21\end{array}$ & $\begin{array}{l}\text { De: } 0.03 \\
\text { Ma: }-0.09\end{array}$ & $\begin{array}{l}\text { De: } 0.00 \\
\text { Ma: }-0.19\end{array}$ \\
\hline $\begin{array}{l}\text { Developmental } \\
\text { culture (DC) }\end{array}$ & $\begin{array}{l}\text { De: } 0.18 \\
\text { Ma: } 0.02\end{array}$ & $\begin{array}{l}\text { De: } 0.33 \\
\text { Ma: } 0.33\end{array}$ & $\begin{array}{l}\text { De: } 0.39^{*} \\
\text { Ma: } 0.11\end{array}$ \\
\hline $\begin{array}{l}\text { Hierarchical culture } \\
\text { (HC) }\end{array}$ & $\begin{array}{l}\text { De: } 0.17 \\
\text { Ma: } 0.26\end{array}$ & $\begin{array}{l}\text { De: } 0.07 \\
\text { Ma: } 0.20\end{array}$ & $\begin{array}{l}\text { De: } 0.41 * * \\
\text { Ma: } 0.32 *\end{array}$ \\
\hline $\begin{array}{l}\text { Rational culture } \\
\text { (RC) }\end{array}$ & $\begin{array}{c}\text { De: } 0.10 \\
\text { Ma: }-0.27\end{array}$ & $\begin{array}{c}\text { De: } 0.05 \\
\text { Ma: }-0.35 \text {, }\end{array}$ & $\begin{array}{l}\text { De: }-0.15 \\
\text { Ma: }-0.13\end{array}$ \\
\hline $\begin{array}{l}\mathrm{R}^{2} \\
\text { Adjusted } \mathrm{R}^{2}\end{array}$ & $\begin{array}{c}\text { De: } 0.12 \\
\text { Ma: } 0.18, \\
\text { De: } 0.06 \\
\text { Ma: } 0.10\end{array}$ & $\begin{array}{l}\text { De: } 0.17^{*} \\
\text { Ma: } 0.09 \\
\text { De: } 0.11 \\
\text { Ma: } 0.01\end{array}$ & $\begin{array}{c}\text { De: } 0.29 * * * \\
\text { Ma: } 0.11 \\
\text { De: } 0.24 \\
\text { Ma: } 0.03 \\
\end{array}$ \\
\hline
\end{tabular}

Table 8 depicts the relationship between the culture-orientations and both perceived methodology support as control and perceived methodology support as cognitive \& co-operation technologies. It shows that the four cultural dimensions, and especially the strength of the HC, explain a significant part of variance of the methodology support as control technology as perceived by developers. It also shows that the four cultural dimensions do not explain the methodology support as cognitive \& co-operation technology. Despite that, the HC exhibits the most significant regression coefficient also here.

Finally, Table 9 depicts the relationship between culture-orientations and perceived methodology impact on the quality of developed systems and the quality and productivity of the SD process. It shows that the four cultural dimensions explain very weakly the quality of developed systems and the quality and productivity of SD process. It shows again that the $\mathrm{RC}$ is negatively associated with methodology impact on the quality of developed systems and the quality and productivity of SD process as perceived by managers. 
Table 8. The relationship between culture orientations and perceived SDM support as control and cognitive \& co-operation technologies

\begin{tabular}{|c|c|c|c|}
\hline & $\begin{array}{l}\text { Support as control } \\
\text { technology }\end{array}$ & $\begin{array}{l}\text { Support for the } \\
\text { common conception } \\
\text { of SD practice }\end{array}$ & $\begin{array}{c}\text { Support for the } \\
\text { evaluation of SD } \\
\text { practice }\end{array}$ \\
\hline & $\beta$ & $\beta$ & $\beta$ \\
\hline $\begin{array}{l}\text { Group culture } \\
\text { (GC) }\end{array}$ & $\begin{array}{l}\text { De: }-0.13 \\
\text { Ma: }-0.19\end{array}$ & $\begin{array}{c}\text { De: } 0.06 \\
\text { Ma: }-0.09\end{array}$ & $\begin{array}{c}\text { De: } 0.16 \\
\text { Ma: }-0.14\end{array}$ \\
\hline $\begin{array}{l}\text { Developmental } \\
\text { culture (DC) }\end{array}$ & $\begin{array}{c}\text { De: } 0.20 \\
\text { Ma: }-0.03\end{array}$ & $\begin{array}{l}\text { De: }-0.01 \\
\text { Ma: } 0.33\end{array}$ & $\begin{array}{l}\text { De: }-0.03 \\
\text { Ma: } 0.18\end{array}$ \\
\hline $\begin{array}{l}\text { Hierarchical cul- } \\
\text { ture }(\mathrm{HC})\end{array}$ & $\begin{array}{l}\text { De: } 0.36^{*} \\
\text { Ma: } 0.15\end{array}$ & $\begin{array}{l}\text { De: } 0.28 \\
\text { Ma: } 0.20\end{array}$ & $\begin{array}{l}\text { De: } 0.13 \\
\text { Ma: } 0.22\end{array}$ \\
\hline $\begin{array}{l}\text { Rational culture } \\
\text { (RC) }\end{array}$ & $\begin{array}{c}\text { De: } 0.04 \\
\text { Ma: }-0.11\end{array}$ & $\begin{array}{c}\text { De: } 0.02 \\
\text { Ma: }-0.18,\end{array}$ & $\begin{array}{l}\text { De: } 0.02 \\
\text { Ma: }-0.20\end{array}$ \\
\hline $\mathrm{R}^{2}$ & $\begin{array}{l}\text { De: } 0.19 * \\
\text { Ma: } 0.09 \\
\text { De: } 0.13 \\
\text { Ma: } 0.01\end{array}$ & $\begin{array}{c}\text { De: } 0.09 \\
\text { Ma: } 0.07 \\
\text { De: } 0.03 \\
\text { Ma: }-0.02\end{array}$ & $\begin{array}{l}\text { De: } 0.05 \\
\text { Ma: } 0.15 \\
\text { De: }-0.02 \\
\text { Ma: } 0.07\end{array}$ \\
\hline
\end{tabular}

Table 9. The relationship between culture-orientations and perceived methodology impact on the quality of developed systems and the quality and productivity of systems development process

\begin{tabular}{|c|c|c|c|}
\hline & $\begin{array}{c}\text { Impact on the } \\
\text { quality of developed } \\
\text { systems }\end{array}$ & $\begin{array}{l}\text { Productivity ef- } \\
\text { fects and morale }\end{array}$ & $\begin{array}{l}\text { Quality effects, } \\
\text { goal achievement } \\
\text { and reputation }\end{array}$ \\
\hline & $\beta$ & $\beta$ & $\beta$ \\
\hline $\begin{array}{l}\text { Group culture } \\
\text { (GC) }\end{array}$ & $\begin{array}{c}\text { De: } 0.07 \\
\text { Ma: }-0.07\end{array}$ & $\begin{array}{c}\text { De: } 0.12 \\
\text { Ma: }-0.16\end{array}$ & $\begin{array}{c}\text { De: } 0.13 \\
\text { Ma: }-0.10\end{array}$ \\
\hline $\begin{array}{l}\text { Developmental } \\
\text { culture (DC) }\end{array}$ & $\begin{array}{l}\text { De: } 0.11 \\
\text { Ma: } 0.17\end{array}$ & $\begin{array}{c}\text { De: } 0.25 \\
\text { Ma: } 0.41\end{array}$ & $\begin{array}{l}\text { De: } 0.04 \\
\text { Ma: } 0.19\end{array}$ \\
\hline $\begin{array}{l}\text { Hierarchical cul- } \\
\text { ture }(\mathrm{HC})\end{array}$ & $\begin{array}{l}\text { De: } 0.07 \\
\text { Ma: } 0.16\end{array}$ & $\begin{array}{l}\text { De: }-0.04 \\
\text { Ma: } 0.10\end{array}$ & $\begin{array}{l}\text { De: } 0.03 \\
\text { Ma: } 0.16\end{array}$ \\
\hline $\begin{array}{l}\text { Rational culture } \\
\text { (RC) }\end{array}$ & $\begin{array}{c}\text { De: } 0.20 \\
\text { Ma: }-0.29\end{array}$ & $\begin{array}{c}\text { De: } 0.09 \\
\text { Ma: }-0.34\end{array}$ & $\begin{array}{l}\text { De: } 0.20 \\
\text { Ma: }-0.39\end{array}$ \\
\hline $\begin{array}{l}\mathrm{R}^{2} \\
\text { Adjusted } \mathrm{R}^{2}\end{array}$ & $\begin{array}{l}\text { De: } 0.13 \\
\text { Ma: } 0.06 \\
\text { De: } 0.07 \\
\text { Ma: }-0.02\end{array}$ & $\begin{array}{l}\text { De: } 0.15 \\
\text { Ma: } 0.10 \\
\text { De: } 0.09 \\
\text { Ma: } 0.02\end{array}$ & $\begin{array}{l}\text { De: } 0.10 \\
\text { Ma: } 0.11 \\
\text { De: } 0.04 \\
\text { Ma: } 0.03\end{array}$ \\
\hline
\end{tabular}

\section{Discussion and Final Comments}

Despite the differences between the respondent groups, the above results provide some support for the conjecture that the deployment of SDMs differ in the four 
empirically derived cultural clusters. They indicate that methodology use did not differ in the four cultural clusters. Also in the case of methodology support as control technology no differences were found. In other cases at least one of the two respondent groups reported cultural differences. It is quite difficult to explain these differences. This leads to a further research question whether different functionalities of SDMs, for example, may differ in their cultural sensitivity.

Table 10 summarises the significant $(\mathrm{p} \leq 0.10)$ coefficients identified in regression analyses (+ for positive and-for negative) ${ }^{3}$. One can clearly see that the HC orientation is most consistently associated with SDM deployment, when assessed by developers: the more hierarchical the culture is perceived to be, the more SDMs are used and the more support they are perceived to provide. The DC is also found to have some positive associations with the methodology deployment, although not systematically. Quite interestingly, the more RC orientation, the more critical management seems to be with regard to the methodology support and impact.

Table 10. Summary of the results of regression analyses

\begin{tabular}{|c|c|c|c|c|c|c|}
\hline & $\begin{array}{l}\text { SDM } \\
\text { use }\end{array}$ & $\begin{array}{l}\text { Support as } \\
\text { production } \\
\text { technology }\end{array}$ & $\begin{array}{l}\text { Support as } \\
\text { control } \\
\text { technology }\end{array}$ & $\begin{array}{l}\text { Support as } \\
\text { cognitive \& } \\
\text { co-ordina- } \\
\text { tion } \\
\text { technology }\end{array}$ & $\begin{array}{c}\text { Impact on } \\
\text { quality of } \\
\text { developed } \\
\text { systems }\end{array}$ & $\begin{array}{c}\text { Impact on } \\
\text { quality and } \\
\text { productivi- } \\
\text { ty SD pro- } \\
\text { cess }\end{array}$ \\
\hline $\mathrm{GC}$ & & & & & & \\
\hline $\mathrm{DC}$ & & De: ++ & & & & Ma: + \\
\hline $\mathrm{HC}$ & De: + & $\begin{array}{l}\text { De: }+ \\
\text { Ma: ++ }\end{array}$ & De: + & De: + & & \\
\hline $\mathrm{RC}$ & Ma: - & Ma: - & & Ma: - & & Ma: - - \\
\hline
\end{tabular}

The relationship between the HC orientation and methodology deployment may be interpreted as reinforcing, implying either that a HC promotes methodology deployment or that SDMs as such are perceived as part and parcel of the HC. As Table 10 indicates the association between the HC and methodology support is confined to developer perceptions. Hypothesising that the HC promotes methodology deployment, the question is why the association between the strength of $\mathrm{HC}$ and perceived methodology deployment differs between developers and managers. One answer in the case of this study may be that developers, who assessed the organisational culture, interpreted SDMs as manifestations of the HC.

Referring to the DC, its positive association with the developers' perceptions of the methodology support as production technology can be explained either as SDMs' direct support for creativity and adaptation to the external environment or alternatively as indirect support for creativity and adaptation through increased order and routinization. The former direct support can be interpreted as reinforcing whereas the

\footnotetext{
${ }^{3}$ The number of + and- signs shows many times the significant beta coefficient was found.
} 
latter is more complementary. This study does not allow testing these alternative explanations in more detail.

The negative association between the strength of the RC and methodology deployment in the case of manager perceptions shows management's critical attitude towards SDMs in organisations which are highly achievement-oriented, focusing on productivity, efficiency and goal achievement. When contrasted with developers, the likely explanation for this is that managers emphasise these goals more than developers. The question is, of course, whether these results really reflect the weakness of SDMs when evaluated on the criteria of productivity and efficiency. Even though one would not agree with the claim, it is also obvious that it is extremely difficult to demonstrate the contribution of SDMs to productivity and efficiency. In view of this uncertainty managers in organisations with a rationally oriented culture may take a more critical attitude towards SDMs. It may also be that the strong emphasis on productivity and efficiency leads to focus on short-run impacts, whereas SDMs' benefits accrue more slowly [8]. In an extreme case, the question may be about IT managers' disappointment with SDMs when projects start to fall behind schedules. It is well-known that SDMs are not very helpful solving these crisis situations and that projects then easily fall into a chaotic ad hoc style of SD without any SDM [17]. Obviously, there is a clear need for additional research on the reasons underlying managers' critical perceptions in rationally oriented organisations.

What are the practical implications of the results? Assuming that the HC supports methodology deployment, the results imply that in organisations with a strong HC orientation the chances of getting SDMs accepted are higher than in organisations with a weak HC orientation. In the latter case, one should pay special attention to measures of introducing SDMs. In organisations with a DC orientation, the results suggest as one possibility to emphasise SDMs' support for creativity and adaptation to the external environment. If the SDM to be introduced does not support them directly, it may be deliberately engineered to comprise these features. A second option is to introduce a SDM as an effective means to make less creative aspects of SD work more ordered and routine, thus freeing developers' time for more creative work.

An alternative interpretation of the association between the $\mathrm{HC}$ orientation and methodology deployment is that SDMs as such are manifestations of the HC. If an organisation does not wish to move into that direction, one should pay special attention to means of avoiding the hierarchical flavour of SDMs when introducing them. One means to make SDMs less bureaucratic is to introduce them as general approaches [18] rather than as complicated conglomerates of numerous techniques with massive documentation. This higher level granularity may also make SDMs more useful as [10] concludes.

\section{References}

1. Allaire, Y. and and Firsirotu, M.E., Theories of organizational culture, Organization Studies, Vol. 5, No. 3, 1984, pp. 193-226 
2. Billings, R.S. and Wroten, S.P., Use of path analysis in industrial/organizational psychology: Criticism and suggestions, Journal of Applied Psychology, Vol. 63, No. 6, 1978, pp. 677-688

3. Cameron, K.S., Effectiveness as paradox: Consensus and conflict in conceptions of organizational effectiveness, Management Science, Vol. 32, 1986, pp. 539-553

4. Cameron, K.S. and Freeman, S.J., Cultural congruence, strength, and type: Relationships to effectiveness, in Woodman, R.W. and Pasmore, W.A. (eds.), Research In Organizational Change and Development, Volume 5, JAI Press Inc, Greenwich, CT, 1991, pp. 23-58

5. Chatzoglou, P.D. and Macaullay, L.A., Requirements capture and IS methodologies, Information Systems Journal, Vol. 6, 1996, pp. 209-225

6. Cooper, R.B., The inertial impact of culture on IT implementation, Information \& Management, Vol. 27, No. 1, 1994, pp. 17-31

7. Denison, D.R. and Spreitzer, G.M., Organizational culture and organizatioanl development: A competing values approach, in Woodman, R.W. and Pasmore, W.A (eds.), Research in Organizational Change and Development, Volume 5, JAI Press Inc, Greenwich, CT, 1991, pp. 1-21

8. Fichman, R.G., Kemerer, C.F., Adoption of software engineering process innovations: the case of object-orientation, Sloan Management Review, Winter 1993, pp. 7-22

9. Fitzgerald, B., Formalized systems development methodologies: a critical perspective, Information Systems Journal,Vol. 6, pp. 3-23, 1996

10. Fitzgerald, B., The use of systems development methodologies in practice: a field study, Journal of Information Systems, Vol. 7, No.3, 1997, pp. 201-212

11. Glass, R.L., Software Creativity, Prentice Hall, Englewood Cliffs, NJ, 1995

12. Hair, J.F.Jr., Anderson, R.E., Tatham, R.L. and Black, W.C., Multivariate Data Analysis with Readings, Macmillan, New York, NY, 1992

13. Hardy, C.J., Thompson J.B. and Edwards H.M., The use, limitations and customization of structured systems development methods in the United Kingdom, Information and Software Technology, Vol. 37, No. 9, 1995, pp.467-477

14. Henderson, J.C. and Cooprider, J.G., Dimensions of I/S planning and design aids: A functional model of CASE technology, Information Systems Research, Vol. 1, No. 3, 1990, pp. 227-254

15. Hofstede, G., Neuijen, B., Ohayv, D.D. and Sanders, G., Measuring organizational cultures: A qualitative and quantitative study across twenty cases, Administrative Science Quarterly, Vol. 35, 1990, pp. 286-316

16. Huisman, M. and Iivari, J., Perceptual congruence in the deployment of systems development methodologies, Proceedings of the $11^{\text {th }}$ Australian Conference on Information Systems, Brisbane, Australia, 2000

17. Humphrey, W.S., Managing the Software Process, Addison-Wesley, Reading, Massachusetts, 1989

18. Iivari, J., Hirschheim, R. and Klein, H., A Paradigmatic Analysis Contrasting Information Systems Development Approaches and Methodologies, Information Systems Research, Vol. 9, No. 2, 1998, pp. 164-193

19. ISO, Information technology- Software product evaluation- Quality characteristics and guidelines for their use, ISO/IEC DIS 9126, ISO, 1990

20. Lewin, A.Y. and Minton, J.W., Determining organizational effectiveness: Another look, and an agenda for research, Management Science, Vol. 32, 1986, pp. 514-538

21. McChesney, I.R. and Glass, D., Post-implementation management of CASE methodology, European Journal of Information Systems, Vol. 2, No. 3, 1993, pp. 201-209 
22. Quinn, R.E. and Cameron, K.S., Organizational life cycles and shifting criteria of effectiveness, Some preliminary evidence, Management Science, Vol. 29, 1983, pp. 33-51

23. Quinn, R.E. and Kimberly, J.R., Paradox, planning, and perseverance: Guidelines for managerial practice, in Kimberly, J.R. and Quinn, R.E. (eds.), New Futures: The Challenge of Managing Organizational Transitions, Dow Jones-Irwin, Homewood, ILL, 1984, pp. 295-313

24. Quinn, R.E. and Rohrbaugh, J., A spatial model of effectiveness criteria: Towards a competing values approach to organizational analysis, Management Science, Vol. 29, No. 3, 1983, pp. 363-377

25. Robey, D. and Boudreau, M.-C., Accounting for the contradictory organizational consequences of information technology: Theoretical directions and methodological implications, Information Systems Research, Vol. 10, No. 2, 1999, pp. 167-185

26. Rogers, E.M., Diffusion of Innovations, Fourth edition, The Free Press, New York, NY, 1995

27. Russo, N.L., Hightower, R. and Pearson, J.M., The failure of methodologies to meet the needs of current development environments, in Jayaratna, N. and Fitzgerald, B. (eds.), Learned from the Use of Methodologies: Fourth Conference on Information Systems Methodologies, 1996, pp. 387-394

28. Schein, E.H., Organizational Culture and Leadership, Jossey-Bass, San Fransisco, CA, 1985

29. Smircich, L., Concepts of culture and organizational analysis, Administrative Science Quarterly, Vol. 28, No. 3, 1983, pp. 339-358

30. Wastell, D.G., The fetish of technique: methodology as a social defence, Information Systems Journal, Vol. 6, No. 1, 1996, pp. 25-40

31. Woodman, R.W. and Pasmore, W.A. (eds.), Research in Organizational Change and Development, JAI Press, Greenwich, CT, 1991

32. Wynekoop, J.L. and Russo, N.L., System development methodologies: unanswered questions and the research-practice gap, in DeGross, J.I et al. (eds.), Proceedings of the Fourteenth International Conference on Information Systems, Orlando, FL, 1993, pp.181190

33. Wynekoop, J.L. and Russo, N.L., Studying system development methodologies: an examination of research methods, Information Systems Journal, Vol. 7, 1997, pp. 47-65

34. Yeung, A.K.O., Brockbank, J.W. and Ulrich, D.O., Organizational culture and human resource practices; An empirical assessment, in Woodman, R.W. and Pasmore, W.A. (eds.), Research In Organizational Change and Development, Volume 5, JAI Press Inc, Greenwich, CT, 1991, pp. 59-81 